\title{
Autoimmune Buerger's Disease Joining Polymyalgia Rheumatica: A Case Report
}

\author{
Michael AB Naafs* \\ Dutch Internist Endocrinologist, Netherlands \\ *Corresponding author: Michael AB Naafs, Dutch Internist Endocrinologist, Health Consultant at Naafs, International Health Consultancy, Netherlands
} Submission: 眥 December 06, 2018; Published: 眥January 16, 2019

\begin{abstract}
In this case report a patient is described with Buerger's disease joining polymyalgia rheumatica (PMR), a combination reported never. A rapidly evolving cascade of autoimmune reactions led to debilitating disease within 3 years. Much research in Buerger's disease Is needed to improve the outlook of these patients.
\end{abstract}

\section{Introduction}

Buerger's disease or thromboangiitis obliterans was first described by Leo Buerger in 1908 as a nonatherosclerotic, inflammatory, segmental vascular occlusive disease of unknown etiology, which involves medium and small arteries and veins of the limbs, only rarely affecting visceral or cerebral vessels [1]. Buerger's disease is rare with a declining incidence of 104 out of 100.000 people in 1947 to 20 out of 100.000 people now [2]. Buerger's disease is strongly linked to tobacco, which is probably a putative antigen as the immune system plays a large role in its development, besides a genetic predisposition [2-4]. In this case report these aspects will be discussed in a patient who developed Buerger's disease following treatment of polymyalgia rheumatica, a combination never reported before.

\section{Case History}

The patient is a 62-year-old male known with Raynaud's phenomenon since his twenties, allergic rhinitis and a mother's family history of autoimmune diseases as polymyalgia rheumatica, giant cell arteritis, retroperitoneal fibrosis, Sjógren's disease and Hashimoto hypothyroidism. Except some child diseases the patient was healthy until the age of 62 . He smoked 20 cigarettes a day and fitness training has been 6-10 hours a week. Returning from a fitness training a 'misstep' on the railway station stairs led to a suspected left groin injury. Multiple physiotherapy courses only resulted n-temporary relief. Because of intractable pain hip X-rays were performed. The left hip showed severe coxarthrosis and he patient was scheduled for total hip arthroplasty, one year after the initial event.

Preoperative screening, including physical examination and lab investigations were considered normal. Postoperative rehabilitation was delayed and complicated by persistent serous wound leakage during 30 days without evidence of infection of the prosthesis. After this period rehabilitation was very slow and typical polymyalgia rheumatica symptoms occurred. Consultation by a rheumatologist confirmed the diagnosis. In retrospection ESR was $68 \mathrm{~mm} / \mathrm{hr}$ and CRP (C-reactive protein) was $168 \mathrm{mg} / \mathrm{L}$ (normal;10mg/L) already at the preoperative screening. Prednisolone $20 \mathrm{mg}$ daily was started, and symptoms were relieved within a few days. Prednisolone was tapered to zero in 9 months guided by symptoms and persistence of normal ESR and CRP.

Nevertheless, walking distance was poor and worsening in the next year to 50-100 meters with intermittent claudication symptoms in both legs, with edema and livido reticularis of the feet. Referral to a vascular surgeon revealed ankle-arm indices on treadmill exercise pointing to a right femoral artery lesion in the presence of completely normal lipid profiles and absence of hypertension. Pulsations of the femoral arteries were palpable. Doppler ultrasound was not conclusive. However, SPECTCT angiography showed no atherosclerotic iliacal or femoral occlusions, but significant infra popliteal segmental occlusions in both legs compatible with the diagnosis Buerger's disease. Treadmill exercise programs and clopidogrel $75 \mathrm{mg}$ daily to prevent arterial thrombosis were started increasing walking distance from $50 \mathrm{~m}$ to 300 meter in one year. The patient quitted smoking. Sports is not possible anymore.

\section{Discussion}

Typical symptoms of Buerger's disease are coldness, numbness, tingling or burning sensations and pain in arms or legs. Raynaud syndrome may develop as well as intermittent claudication. Cramps occur in the calf muscles. As the disease progresses cramps become more painful and last longer. Late in the disease skin ulcers or gangrene or both may appear usually on one or more toes or fingers. The foot or hand feels cold and may turn bluish probably because blood flow is greatly reduced. Critical limb ischemia can be caused by arterial thrombosis [2]. In this case report Raynaud 
phenomenon has been present 40 years before diagnosis of Buerger's disease, now turning into Raynaud syndrome, therefore. Severe allergic rhinitis presented 20 years earlier. Tobacco, also named as a putative antigen in the residual inflammation of atherosclerosis [5] has been present 50 years before Buerger's diagnosis. Genetic predisposition has been present 62 years in this patient. HLA (human leukocyte antigen) typing was not performed because it does not add to diagnosis and management [2].

Polymyalgia rheumatica (PMR) was not recognized in the preoperative screening and could have exacerbated left hip coxarthrosis. Anyway, PMR should be treated before performing a THA (total hip arthroplasty). The persistent wound leakage of 30 days must be seen as an exaggerated immune response to a foreign body in the presence of untreated PMR [6]. Buerger's disease joining PMR has not been described before in the literature. How this cascade of autoimmune reactions and disorders could take place in three years remains highly speculative as e.g. viral infections etc. Cure is not possible and new therapies as mesenchymal stem cell transplantations failed [7] Sports is not possible anymore in this patient [8]. A lot of research in Buerger's disease will be needed in the future to improve the outlook of these patients.

\section{References}

1. Buerger L (1908) Thromboangiitis obliterans: A study of the vascular lesions leading to presenile spontaneous gangrene. Am J Med Sci 136: 567-580.

2. https://www.rarediseases.info.nih.gov/diseases/5569/buergerdisease/

3. Vijayakumar A, Tiwari R, Prabhusawawy VK (2013) Thromboangiitis Obliterans (Buerger's Disease) ; Current Practices. Int J Inflam, pp: 1-9.

4. Kobayashi M, Ito M, Nakagawa A, Nishikimi N, Nimura Y (1999) Immunohistochemical analysis of arterial wall cellular infiltration in Buerger's disease (endarteritis obliterans). J Vasc Surg 29(3): 451-458.

5. Naafs MA (2018) New Insights into Inflammation in Atherosclerosis. Glob J Endocrinol Metab 2(4): 1-6.

6. Naafs MA (2018) Persistent Wound Leakage After Total Knee and Hip Arthroplasty. Orthop \& Spo Med Op Acc J 1(4): 55-59.

7. Cacione DG, Do Carmo Novaes F, Moreno DH (2018) Stem cell therapy for treatment of thromboangiitis obliterans (Buerger's disease). Cochrane Library.

8. Naafs MA (2018) Fitness and Sports After Total Joint Arthroplasty. J Phy Fit Treatment \& Sports 4(5): 1-5.
Creative Commons Attribution 4.0 International License

For possible submissions Click Here

\section{Submit Article}

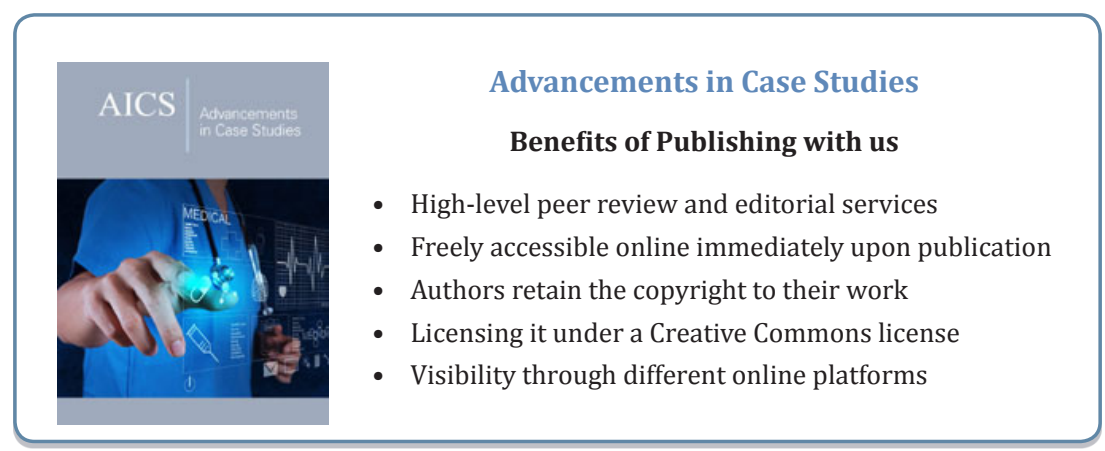

